\title{
Design and Development of a Video Game to Assess Problem-Solving Competence in Chemistry Education
}

Amany Annaggar · Rüdiger Tiemann*

\begin{abstract}
It is a great challenge to design and develop an educational video game that can assess problem-solving competence in chemistry education. Developing an educational game requires both pedagogical and game contents. The primary challenge is to combine these two main parts and find a method to develop this product as a digital environment. Current work presents the design and development process of a 3D educational adventure video game. For this purpose, the researcher conducted in-depth interviews with science teachers $(\mathrm{N}=7)$ and high school students $(\mathrm{N}=19)$ to assess their assumptions and needs before developing the game. The insights afforded by the interviews and the theoretical background guided the researcher to design the ALCHEMIST game. The design of ALCHEMIST is based on the Berliner problem-solving model and self-determination theory to engage students, and to assess problem-solving competence in a chemistry lesson. ALCHEMIST is designed to be used as an assessment tool for problem-solving competence by applying tasks, quests, conducting simple experiments in the virtual lab and problem-solving questions with three levels of performance. In the following, the methods used and design phases are discussed in more detail.
\end{abstract}

\section{Keywords}

Chemistry Education; Problem-solving competence; Assessment tool; Video game; Design; Development

\author{
Amany Annaggar \\ Chemistry Education, Humboldt-Universität zu Berlin, Brook Taylor Str. 2, \\ Berlin, Germany \\ *Rüdiger Tiemann \\ Chemistry Education, Humboldt-Universität zu Berlin, Brook Taylor Str. 2, \\ Berlin, Germany \\ E-mail: ruediger.tiemann@chemie.hu-berlin.de \\ Telefon: +49 [30] 2093-7510/7575 \\ Fax: +49 [30] 2093-7482/6985
}




\section{Introduction}

Game-based learning has become widespread in the last few years (Huynh-Kim-Bang et al. 2010; Zichermann 2010; Prensky 2001). It is defined as the use of video games combining the constructs of fun and learning at the same time, and stimulating the pleasure of the learning process (Perrotta et al. 2013). Game-based learning helps teachers and learners to connect the knowledge gained in classrooms (Malone and Lepper 1987; Habgood and Ainsworth 2011; Clark and Martinez--Garza 2012). The game is an artwork in which players are engaged in an artificial conflict, defined by rules, that results in an assessable outcome (Salen and Zimmerman 2004). Hence, it allows students to make the right decision about what to do for the next step. Video games can motivate students to learn (Mitchell and Savill-Smith 2004; Paraskeva et al. 2008; Prensky 2001; Tüzün et al. 2009), and can improve cognitive skills such as critical thinking and problem-solving competence (McFarlane et al. 2002; Valerie Shute and Ventura 2013; Eow et al. 2009). Furthermore, it makes the learning process visible, and it can be used to determine the students' strengths and weaknesses regarding educationally valuable competencies. This is because video games have many characteristics such as challenge, interactivity, feedback, emotional reaction, abstract, control, quantitative outcomes, aesthetics, and fantasy (Kapp 2012; Garris et al. 2002). They also have various components like avatars, badges, leader-boards, points, levels, tasks and many more, where students can interact with the game and be kept motivated (Baylor and Kim 2005). Combining these game components and characteristics, and applying them to different educational aspects can motivate students and improve their problem-solving competence. This can lead to further engaging and enjoyable activities (Kim and Grunig 2011). For these reasons, game-based learning can provide alternative forms of assessment, and they can be used to develop environments that support improving the learning process(V. Shute and Wang 2009; V. J. Shute et al. 2016). 
Video games can measure the students' performance in a broad variety of tasks, teach valuable life skills and assist in setting goals. Researchers of game-based-learning believe that the use of video games in teaching is essential to support and foster skills such as collaboration, communication and problem-solving for future jobs (V. J. Shute et al. 2013). The most notable feature of video games compared to any other learning tool is the combination of motivation, simulation, engagement, fun, collaboration and data collection that cannot be achieved by any other means. This leads to an increasing interest across the board of the educational establishment to use video games as serious learning and assessment tools. Games seem to foster higher-order thinking skills such as planning and reasoning, more than content knowledge(Ke 2009).

Recently, researchers proved that well-designed video games could be used to assess constructs, e.g., creativity, design thinking, gaming the system, persistence and problem-solving skills (Valerie Shute and Ventura 2013; V. J. Shute et al. 2013). There is a consensus among researchers that problem-solving competence is an essential learning outcome for both academic and professional careers (Greiff and Funke 2009; Wirth and Klieme 2003; Klieme 2004). Problem-solving is important and valuable competence in chemistry education, because it is what chemists do (Bodner and Herron 2003).

Table 1 The Berliner problem-solving model (Koppelt and Tiemann 2008)

\begin{tabular}{|l|l|}
\hline $\begin{array}{l}\text { Understanding and characterizing } \\
\text { the problem (UCP) }\end{array}$ & $\begin{array}{l}\text { The first phase of problem-solving in which students have to } \\
\text { understand and simplify the problem situation and to identify } \\
\text { the relevant information. }\end{array}$ \\
\hline Representing the problem (PR) & Students have to build an adequate mental model \\
\hline Problem-solving (PS) & $\begin{array}{l}\text { Students have to solve the problems depending on the } \\
\text { information given and the model. }\end{array}$ \\
\hline $\begin{array}{l}\text { Reflecting and communicating the } \\
\text { solution (RCS) }\end{array}$ & $\begin{array}{l}\text { Students evaluate and communicate the problem`s } \\
\text { solution. }\end{array}$ \\
\hline
\end{tabular}

Problem-solving is a very complicated human activity, and it is an essential and integral part of chemistry which helps to understand its concepts, principles and methods. This skill is required whenever students are challenged with a previously encountered 
situation, when they need to apply already acquired knowledge to address the problem (Kapp 2012). According to the general definition of problem-solving, it [...]" an individual capacity to engage in cognitive processing to understand and solve problem situations where a solution is not immediately apparent. It includes the willingness to participate in such situations to achieve one's potential as a constructive and reflective citizen" (OECD 2013). To solve problems in the context of chemistry, students have to follow scientific steps or a scientific model. In this regard, the Berliner Model of complex problem-solving was proposed (Koppelt and Tiemann 2008; Scherer et al. 2014). It consists of four phases, as shown in Table 1. Therefore, problem-solving practices as a part of the constructive learning theory are of particular interest in innovative learning environments Groff (2013).

Jonassen (2004) proposed that there are eleven different kinds of problems. For special interest in game-based learning, we can focus on types such as case analysis, story problems, decision-making, troubleshooting and design problems. These problem types vary along the spectrum from well-structured to ill-structured. The solving of wellstructured and ill-structured problems engages substantially different cognitive processes (Jonassen and Kwon 2001; Shin et al. 2003). The problem-solving strategy is helping students in chemistry education to improve creative thinking, self-regulated skills and selfevaluation (Yoon et al. 2014). Problem-solving can improve communication and motivate students to improve their learning skills (Cutumisu and Bulut, 2017; OECD, 2013). Angawi (2014) stated that using problem-solving strategies in chemistry classes can stimulate the students' thinking and enhance their learning and understanding abilities (Angawi 2014). It is essential to view problem-solving competence as a fundamental concept in science education. Assessing problem-solving refers to collecting, then analyzing, information about a student's understanding and performance in solving given problems (Angawi 2014). Problem-solving competence seen as a fundamental concept in science education, is essential to measure and assess the students' problem-solving competence. Assessing problem- 
solving refers to collecting, and then analyzing information about a student's understanding and performance in solving given problems Angawi (2014).

Table 2 Three levels of problem-solving proficiency (OECD, 2003)

\begin{tabular}{|l|l|}
\hline High-level performers & $\begin{array}{l}\text { Students at this level can develop complete and coherent mental } \\
\text { models of different situations. They can find an answer through } \\
\text { target exploration and methodical execution of multi-step plans. }\end{array}$ \\
\hline Moderate-level performers & $\begin{array}{l}\text { Students at this level can control moderately sophisticated devices, } \\
\text { but not always efficiently. They can handle multiple conditions or } \\
\text { interrelated features by controlling the variables }\end{array}$ \\
\hline Low-level performers & $\begin{array}{l}\text { Students at this level can answer if a single specific constraint has to } \\
\text { be taken into account. They can partially describe the behavior of a } \\
\text { simple topic }\end{array}$ \\
\hline
\end{tabular}

To assess problem-solving competence, there are three levels of proficiency as shown in table 2 (OECD, 2013). The assessment of problem-solving competencies provides educators and policymakers with critical indicators for the quality and outcomes of educational systems (Wirth and Klieme, 2003).

Also, the assessment of problem-solving competencies makes it possible to understand whether educational systems provide students with the knowledge and skills they need for successful professional and social endeavors (Wirth and Klieme, 2003). Assessing problem-solving mostly requires the use of computer-based technology because dynamic problem-solving situations often consist of many variables (Jonassen, 2000; Hartig et al. 2008; Klieme, 2004), which makes it difficult to account for such variables using paper and pencil instruments (Chung et al. 2002; Greiff and Funke, 2009; Reeff et al. 2006). As already mentioned, video games provide an ideal system to present problemsolving situations and the dynamic variables through game components, in order to assess problem-solving competencies (Shute and Wang, 2009; Schrope, 2013; Shute et al. 2016).

Mekler and Peng, along with their colleagues, argued that video game features can also motivate learners in an effective qualitative way when they support the three basic psychological needs innate to everyone (Mekler et al. 2017; Peng et al. 2012). In other 
words, video games can be used to achieve the key elements of self-determination theory (SDT) by using the game characteristics and components in a proper design model (Deterding, 2012). According to the self-determination theory, the three most important factors in every game are competence, autonomy, and relatedness. When these factors are present, intrinsic motivation can be achieved (Ryan and Deci, 2000), and the game can provide a meaningful experience, mastery, and autonomy (Deterding, 2012). Yee (2006) described these factors as follows:

Competence means achieving something within the activity. For example, solving problems, overcoming obstacles, accomplishing something, making progress toward mastery, or applying frequent and direct feedback. This factor can be implemented in the game within the elements of feedback, progressive information, points, levels and challenges. Competence in game design makes the game rules and goal clearer and more structured, and they measure the player's performance in multiple ways. This factor can engage the students behaviorally and emotionally (Yee, 2006).

Autonomy is about being in control, experimentation, customization and making meaningful choices. This factor is presented in the elements of avatars, quests, tasks or quizzes. Autonomy provides different ways for the players to reach their goal. This factor can engage the students' emotions.

Relatedness means that playing the game is connected to something meaningful; there is social interaction and discussion within the game, as well as a sense of purpose or goal. Relatedness also provides opportunities to collaborate in the game. This factor can engage the students' behaviors, emotions, and cognitive processes (Yee, 2006).

Therefore, this study aims to present how these learning and motivation theories could be applied in a video game to assess problem-solving competence in chemistry education. 


\section{Research Aim}

The aim of this research is to present the main design principles which guided the design, and to develop a video game-based assessment tool for problem-solving competence in chemistry education. The framework of this study goes through the following workflow:

1. Literature review relating to the aspects of assessing problem-solving competence, motivation theories, design, and development educational games. This will also help to determine which model should be followed to design and develop a video game as an assessment tool.

2. A pilot study by conducting in-depth interviews with teachers and students. The aim of the interviews is to learn the assumptions of teachers and students regarding an educational video game with scientific content.

3. Determine the video game components that can be used to present the problem-solving model and self- determination theory.

4. Design and development of the game.

\section{Participants}

In the context of the pilot study to understand the needs of the teachers and students, seven science teachers and nineteen high school students were part of the study. During the game development, four chemistry education researchers were a part of the quality assurance test. In addition, three ninth-grade students were part of the game-play evaluation (See fig 1). 


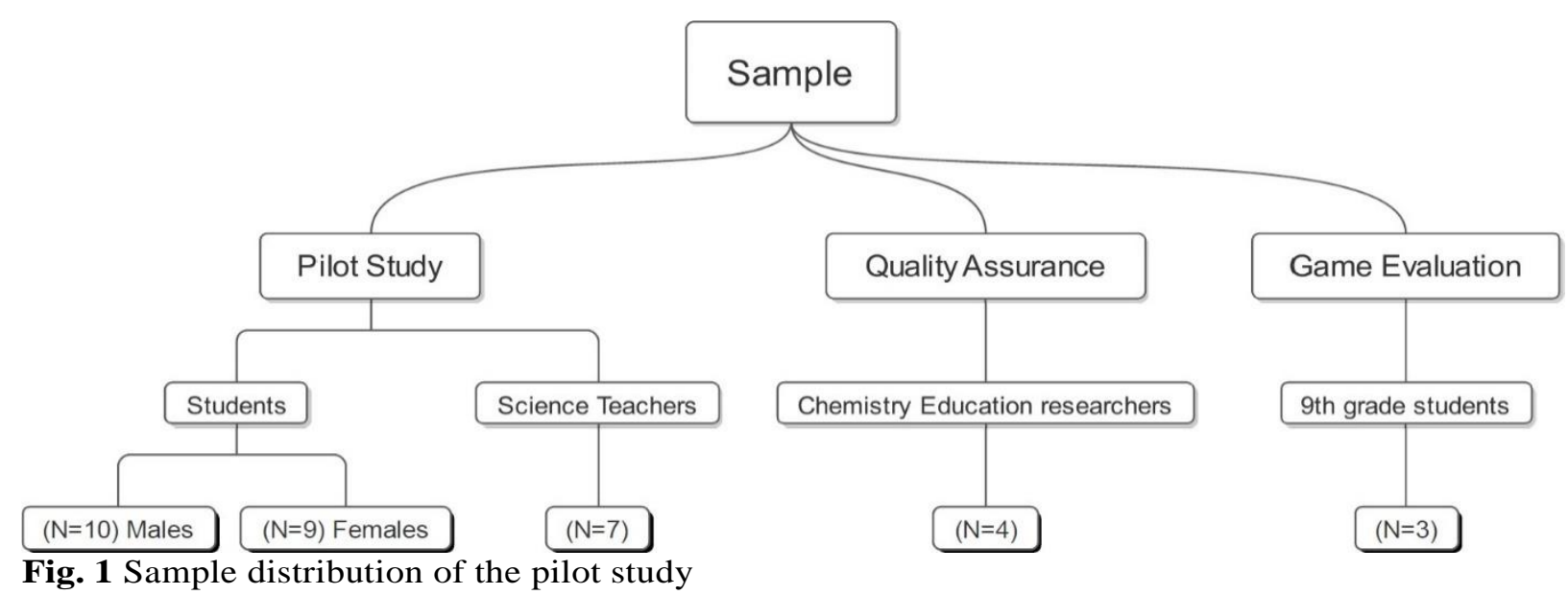

\section{In-depth Interview}

To successfully develop an educational game that should attract teachers and students to use the game as main users, it was essential to include them in the study to know their needs. For that reason, the research is an impartial survey of what teachers and students really need. The interview questions focused on the participants' needs and assumptions for an educational video game with scientific content to assess problem-solving competence. The interviews were audio-recorded and transcribed to present the main information needed to be used as a guide during the game design.

\section{Interviews' results}

The following results present the assumptions of teachers and students of the educational game with scientific content.

\section{Teachers' insights}

The participants were science teachers in Berlin high schools (7th- 12th grades) with teaching experience of between one and 22 years. The transcriptions and the analysis of the protocols showed that the challenges ranged from keeping students motivated and engaged to learn science, to assessing their competencies; this is not being incorporated in traditional teaching methods and paper-pencil tests. Some teachers discussed the difficulty of linking a lot of concepts in science to 
the real world, where students cannot relate to the concepts or understand them. Teachers argued that the benefits of integrating games outweigh the disadvantages, and one teacher specified that games help science to be "less teaching and more learning". This game also offers students a customized learning experience. Another challenge discussed was that students are bored with the traditional teaching methods and that they get highly motivated when they get to play interactive games in class. As a chemistry teacher explained, "Students always ask for games".

Regarding the design of the game, all teachers agreed that a game they would consider successful is one that includes one concept with a multi-level feature, where the game would be customized according to the students' knowledge. All teachers agreed they would prefer a traditional story scheme from a cross-curricular point of view. However, knowing their students, they opined that students would be more interested in playing a game that is based on a fictional world. The duration of the game recommended by teachers was 40 to 90 minutes to fit with the lesson duration. All teachers agreed that it would be beneficial to have a tool which tracks student progress and derives analysis in the form of points or charts, to give the teacher a view of where each student is on the learning curve. This feature includes collecting results of quizzes taken by each student and mapping them along with other students' scores. The following Table 3 summarizes the needs of teachers and students in the game.

Table 3 Teachers' and students' insights about the game design

\begin{tabular}{|c|c|c|}
\hline & Teachers' insights & Students' insights \\
\hline Game Features & $\begin{array}{l}\text { - Trial and error learning } \\
\text { - Quiz at the end } \\
\text { - Rewards }\end{array}$ & $\begin{array}{l}\text { - Virtual lab } \\
\text { - Game money "Gifting System" } \\
\text { - Avatar } \\
\text { - Tasks } \\
\text { - Multiplayer } \\
\text { - Points }\end{array}$ \\
\hline Game Story & $\begin{array}{l}\text {-Perseverance should be re- } \\
\text { warded" } \\
\text {-Clear link and coherent story } \\
\text { plot }\end{array}$ & $\begin{array}{l}\text { - Easy to understand and follow } \\
\text { through it. } \\
\text { - Game has a story behind Cinematic } \\
\text { moments } \\
\text { - Easy, medium and hard }\end{array}$ \\
\hline
\end{tabular}




\begin{tabular}{|c|c|c|}
\hline & $\begin{array}{l}\text { - Easy to understand and follow } \\
\text { through }\end{array}$ & - modes of play \\
\hline Game Design & $\begin{array}{l}\text { - "In a way that students can't } \\
\text { cheat" } \\
\text { - Motivating \& engaging } \\
\text { elements } \\
\text { - Challenging, alter difficulty ac- } \\
\text { cording to what the student level } \\
\text { is. } \\
\text { - Hands on experience, not only } \\
\text { theory }\end{array}$ & $\begin{array}{l}\text { - Challenging } \\
\text { Would like to see the effects of tasks } \\
\text { accomplished in the game } \\
\text { - Not fast paced } \\
\text { - Concrete well defined task/mission } \\
\text { - First person game }\end{array}$ \\
\hline Game Interface & $\begin{array}{l}\text { - Graphics up to international } \\
\text { - standards and appeal to students } \\
\text { of that age group }\end{array}$ & $\begin{array}{l}\text { - Design a different theme to each } \\
\text { game level } \\
\text { - Animation and real graphics } \\
\text { - Connection between sound and } \\
\text { movement } \\
\text { - Exciting, having threats and action }\end{array}$ \\
\hline Game Objectives & $\begin{array}{l}\text { - Meet specific learning goals. } \\
\text { - Tied to learning outcomes } \\
\text { which are communicated to } \\
\text { students and teacher. } \\
\text { - Based on the German school } \\
\text { curriculum }\end{array}$ & $\begin{array}{l}\text { - Clear ending for the game } \\
\text { - Not just about answering questions } \\
\text { - Learning through playing } \\
\text { - Having fun while learning } \\
\text { - „Creating a sense of competition” }\end{array}$ \\
\hline
\end{tabular}

\section{Students' insights}

Taking game idea feedback from the actual user, as well as understanding in general what they are looking for in an educational game, is essential to the success of the game. We conducted 19 indepth interviews lasting from 20 to 30 minutes each over the course of a month. Interviewees were students from the 8th and 9th grades, ten males and nine females. The interviews were guided by questions derived from the research objectives. These interviews were very enlightening, where some of our initial vision for the game was accepted and liked by the students, and other new ideas for game features were also introduced. Students have given us an overall idea for game development and were considered a first step to understanding our target group (Table 3).

\section{Design and Development of ALCHEMIST}

Based on the insights of the interviews with teachers and students, the researcher came up with the idea of "ALCHEMIST". The game's story is based on the novel by Paulo Coelho (1993). The 
features were designed to meet the teachers' and students' needs and learning objectives. After building the game idea and purposes, the researcher followed a development model (Zin et al. 2009) to design and develop ALCHEMIST. The development process of the educational assessment game focused on the methodology to produce a video game. Figure 2 illustrates the proposed method which consists of five main phases (Zin et al. 2009) with some modification in the details from the researcher to design the game.

The design and development went through five phases as follows:

\begin{tabular}{|c|c|c|c|c|}
\hline \multicolumn{5}{|c|}{ Development methodology for ALCHEMIST } \\
\hline Analysis & Design & Development & Quality Assurance & $\begin{array}{l}\text { Implementation } \\
\text { and Evaluation }\end{array}$ \\
\hline $\begin{array}{l}\text { - Requirements } \\
\text { and problem } \\
\text { analysis } \\
\text { - Statement of } \\
\text { learning } \\
\text { objectives } \\
\text { - Determnation of } \\
\text { game idea }\end{array}$ & $\begin{array}{l}\text { - Instructional } \\
\text { design } \\
\text { - Game design } \\
\text { - Prototype }\end{array}$ & $\begin{array}{l}\text { - Develop the } \\
\text { game plan } \\
\text { - Charachters } \\
\text { - Programming } \\
\text { - Art production } \\
\text { - Audio production } \\
\text { - Testing }\end{array}$ & $\begin{array}{l}\text { - Check game's } \\
\text { content } \\
\text {-Check game's } \\
\text { quality } \\
\text {-Improve game's } \\
\text { quality }\end{array}$ & $\begin{array}{l}\text { - Evaluation and } \\
\text { modification } \\
\text { - Launchung }\end{array}$ \\
\hline
\end{tabular}

Fig. 2 Development Methodology of ALCHEMIST

\section{Analysis Phase}

The first phase aims to determine the learning goals, problems, and requirement analysis, based on the curriculum for 9th-grade students in Berlin and Brandenburg. The main aim was to assess the students' achievement and the problem-solving competence for the chemistry concepts of acids, bases, and $\mathrm{pH}$ value. The game idea and story were also determined, as well as the game platform. The analysis phase includes:

- Requirements and problem analysis: the researcher determined the stakeholders, the problems and the main goal of the game. The stakeholders are 9th-grade students who need to learn a chemistry concept and assess their problem-solving competence through the game features. The game uses Unity 3D software as a development engine and Windows PCs as a platform, based on the available resources and available devices in schools. 
- Determination of the game idea: based on the literature and the in-depth interview results, the researcher determined the game idea, story and features. The aim is to develop a 3D video game based on a fantasy story, with three performance levels to be achieved. The game story came from the novel The Alchemist, so the game is called ALCHEMIST.

\section{Design Phase}

The game design document was written based on the pedagogical content and the game style to achieve the game goal as follows:

\section{Pedagogical design:}

The scientific content was determined and improved to cover the learning objectives and the curriculum need. The topic of the game covered a chemistry concept in the 9th-grade curriculum about acids, bases and the $\mathrm{pH}$ value. The design includes:

- The problem-solving model with four problem-solving steps was determined in Table 1.

- Lesson Plan: scientific content with one concept was applied as teachers required, and written based on the chemistry curriculum in Berlin.

- Constructivism theory was presented in the game design as tasks, quests, problems, questions, collaboration and conducting experiments in a virtual lab (Jonassen, 1999). Problem-solving questions with three levels of proficiency (Table 2).

- Factors of self-determination were applied in the game to motivate students along the gameplay (Ryan and Deci, 2000). The competence factor is represented by feedback following information, points, levels and challenges. Anatomy factor is presented in these elements (Avatar, Quests, Tasks, Quiz). Relatedness is introduced through chatting with the characters in the game via a dialogue system. 


\section{Game style design:}

Based on the pedagogical design and the results of the interviews, the game elements and their types were determined as follows:

- The game content is applied in an interactive conversation system. Prepare the introduction video and the graphics.

- The game elements were determined also in this phase which contains: constrain, narrative, progression, relationships, emotions, missions, competition, cooperation, transactions, rewards, fighting, feedback, avatars, points, levels and the performance graphs.

- The scenario and storyboard cover the learning objectives and curriculum requirements. The game story and scenario based on the four phases of the problem-solving model to tell the story as follows:

- At the beginning of the game scenario, the avatar starts in front of a school building. He has to understand his mission and get quests. Then he has to travel through the time machine to Alchemist City, then go out of the city to the jungle. These three main places present the journey and balance the game design rules (Salen and Zimmerman, 2004).

- The story is based on the conversation system, so the player has to contact the characters in the game to collect information and get the tasks. As the player contacts people and gets more information, he or she will get more experience points and move up the levels. The game includes some quizzes and some quests. For each answer or task, the player can earn between one and six points depending on his creativity and performance. This presents the third game design rule of creating an experience. The points to be gained are set based on the player's 
performance, because the quizzes consist of problem-solving questions with three correct answers, each answer reflecting the understanding level (Table 2). The low- level answer is the easiest one. In this case, the student gets only one experience point. The intermediate level reflects if the student understood the given information and answered the expected answer, and in this case, the student gets three experience points. The high-level answer is the most complex one; it reflects that the student understood the concept and connected the information. In this case, the students will get six experience points.

- The game contains a virtual laboratory to allow the player to prepare and conduct simple experiments and to solve the main problem, which is a differentiation between acids and bases.

- The evaluation of the player could be done in two ways. The first way is from the experience points. Collecting less than 90 points is an indicator of a low performer. The player who collects between 91 and 180 is an indicator for a moderate performer. The high-performance player can collect more than 180 points with a maximum of 210 points, which means that the player solved all tasks and quests, and answered most of the questions of the high performing level. The second way is from the log file, which helps to assess the student's problem- solving competence and evaluate them in each problemsolving phase in particular, and the students' pathway in the game. This part could help teachers to evaluate the strengths and weaknesses of students in each phase.

\section{The prototype:}

For the interface was designed on paper. The researcher asked four expert chemistry education researchers and five students about what they expect to see and the use of the elements before starting in the development phase. 


\section{Development Phase}

This is the most important and difficult phase of the game development process. The researcher has to develop the game elements and the pedagogical components. The development of the complete game is done by the researcher herself as follows: system, quizzes, fighting, points, levels, quests and the virtual lab platform.

- The researcher started with the development of the game plan and terrain using Unity 3D, which is the geographic area of the game.

- The game journey goes through three main places in the game narrative, therefore the terrain consists of two parts. The first one is a modern world, and the second one is an old city and jungle. The game components and assets were chosen from the asset store or designed to build the game interface as shown in Figure 3.

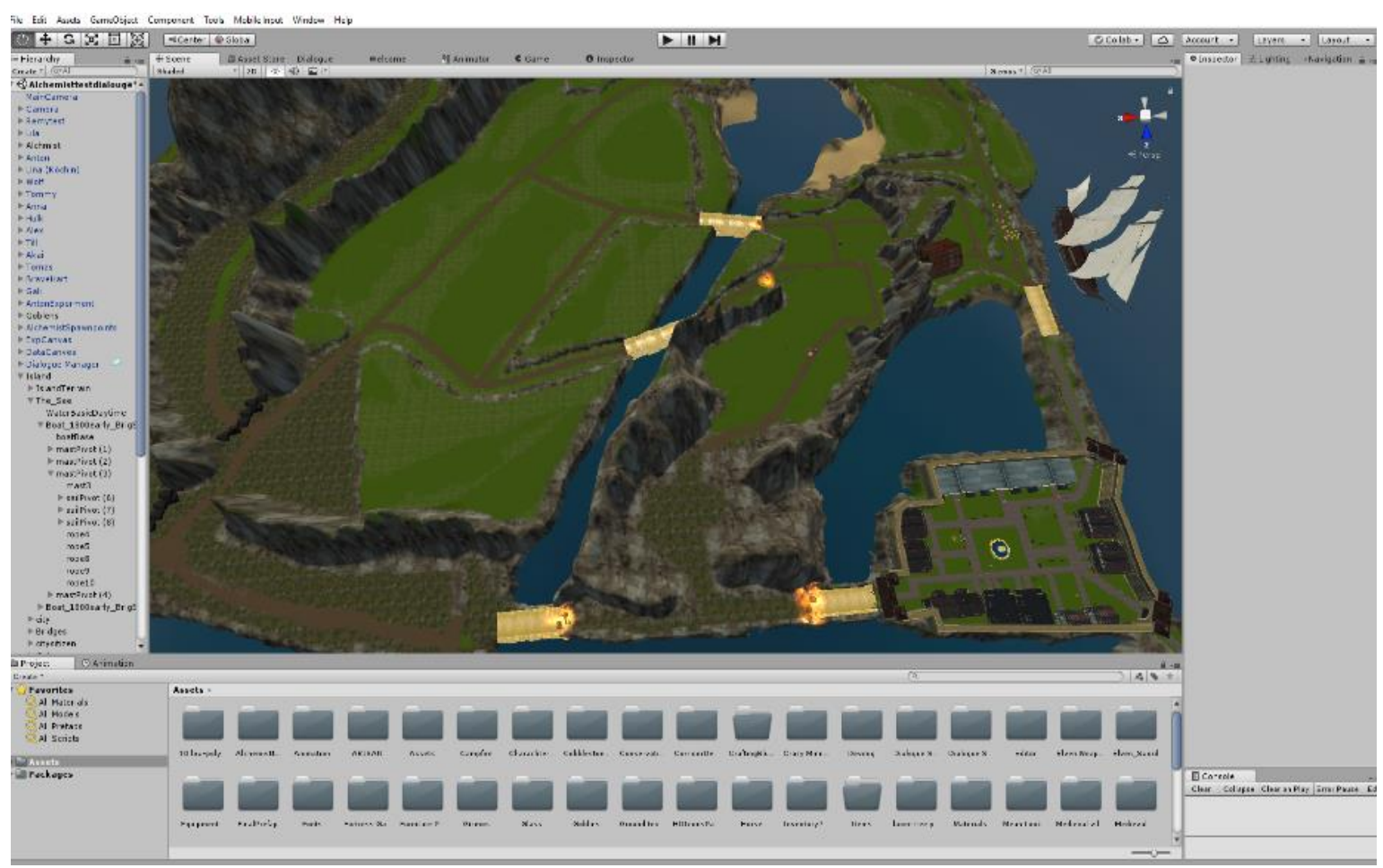

Fig. 3 Screenshot from the game environment design

- The characters' avatars were designed by Blender Software Foundation (n.d.). Ten main characters in the game were developed, including the player's avatar and seven soldiers in front of the gates who posed the main quizzes. In addition, other characters are either 
lost in the jungle or simply walking through the city. The goblins were downloaded from the asset store based on the game story.

- The dialogue system was developed based on the scenario and the storyline to implement the scientific content, problem-solving questions and the quizzes as shown in Figure 4 following the pedagogical design. In this system, the researcher worked with the points, levels up, and set the conditions to fit with the problem-solving phases and pedagogical design requirements.

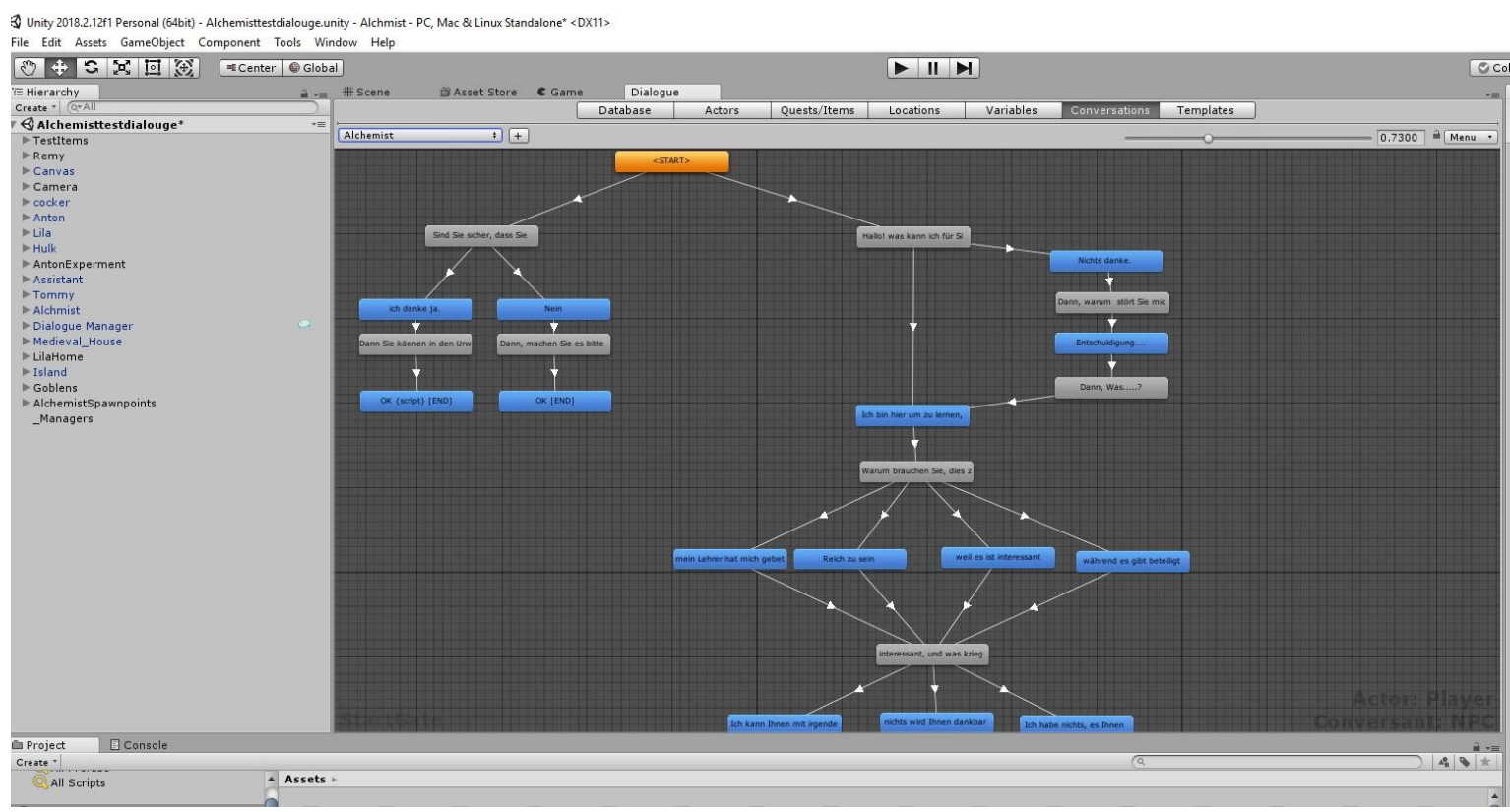

Fig. 4 Screenshot for the dialogue system

- After finishing the dialogue system, the researcher asked some voice actors to record the dialogue to motivate the player to interact and to increase the social presence; the game music was chosen to describe the audiovisual performance (Nasrudin et al. 2017). 
- Coding the game conditions: after finishing the dialogue development, the researcher coded the game conditions to fit with the game's aim and rules. As shown in Figure 5, the game condition codes are written by C\# language.

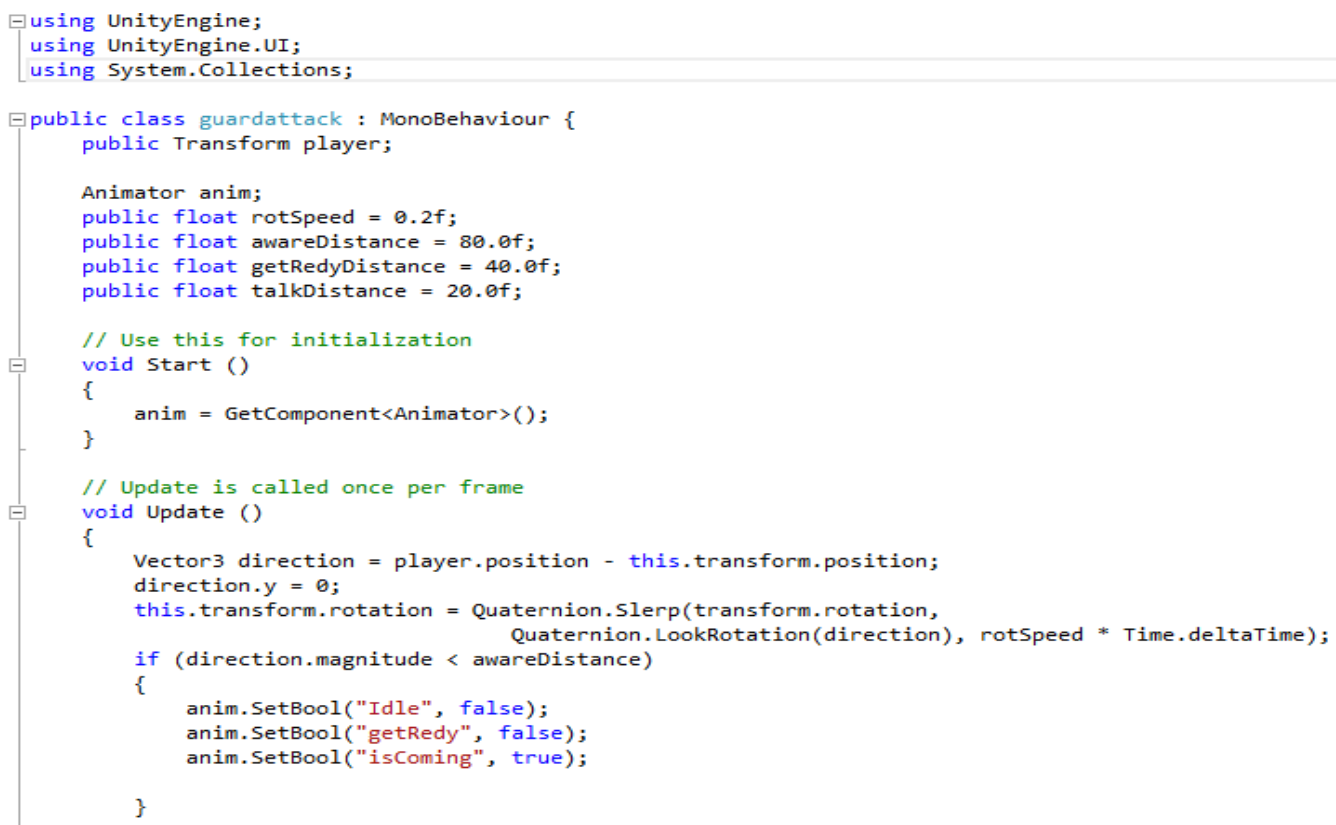

Fig. 5 Screenshot for coding a condition

By the end of this phase, a complete game was achieved, with an average of 50 minutes playing time with many features to fulfil the aim of the game as shown in Figure 6.

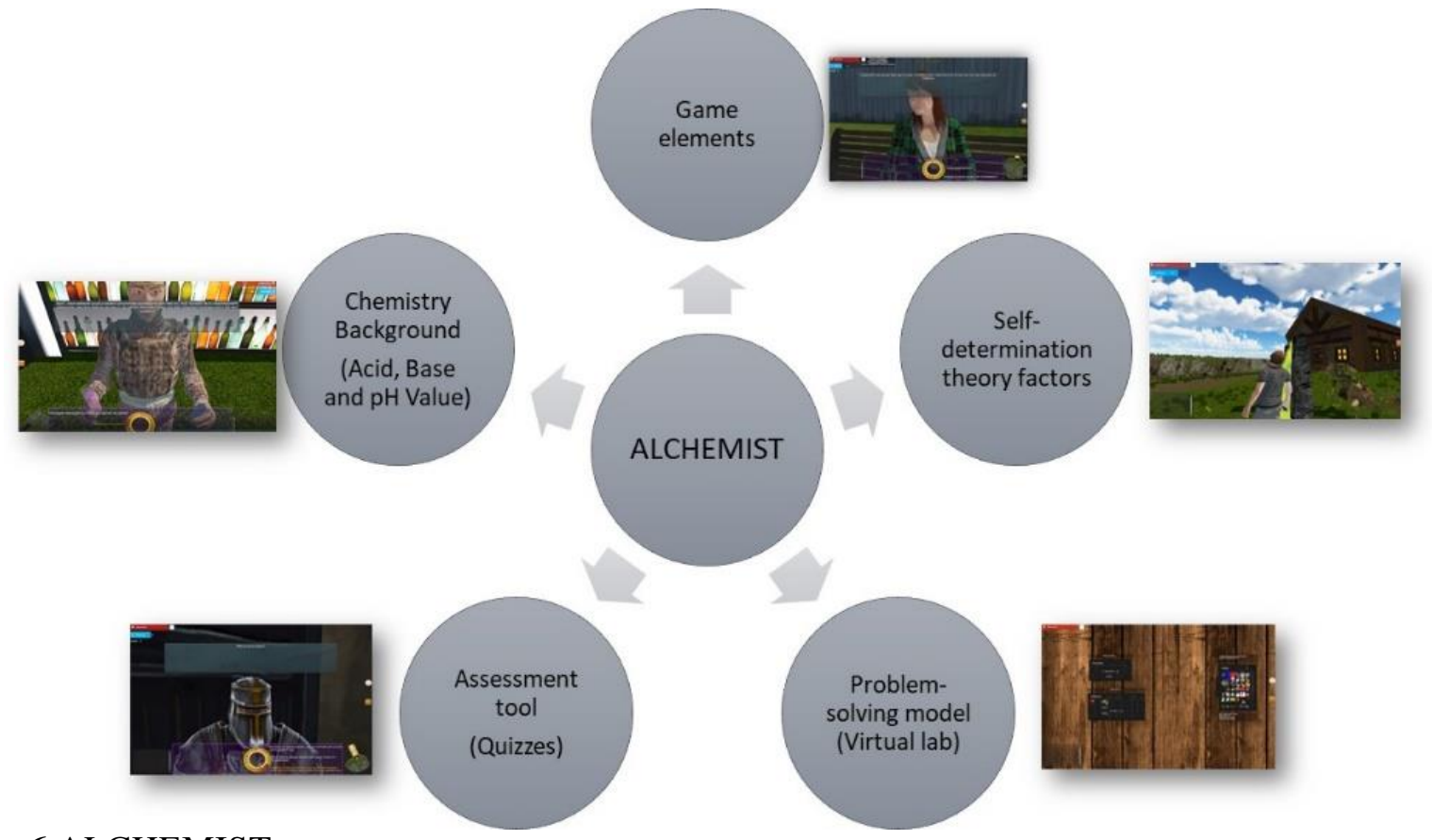

Fig. 6 ALCHEMIST components summary 


\section{Quality assurance}

After the development phase, the researcher and developer had to assure the quality of the game. The researcher followed the following to test the game quality:

- Check the game content and the game flow, to check the scientific content, language and technical errors or bugs.

- Improve the game quality: improve the performance of the game and its speed on the devices, also the gameplay and find if there are any problems in the game interface.

For this purpose, the researcher asked four chemistry education researchers to check the game. The researcher used their comments to modify the dialogue and game errors to prepare the game for launch. Thus the programs are ready for trial in the field. The main changes included: resize the font of the text; change the font color; change some gameplay conditions and fix some technical bugs.

\section{Launching}

After the quality assurance phase, the game was thoroughly tested and launched on the PCs to confirm that it was running. For that purpose, the researcher asked three 9th grade students who understood the content and had experience in playing games to play the complete game using the think-aloud method. Then a guided interview was conducted to get their opinion on the game design and the game idea (Figure 7).

The interview questions cover the following points: game design, gameplay and game narrative, game fun, the presenting of the scientific content, and the game goal. The students agreed that the game was working very well on the device; that it was interesting and appropriate, and valid for the application. 
Fig. 7 Photoshoot during the evaluation phase

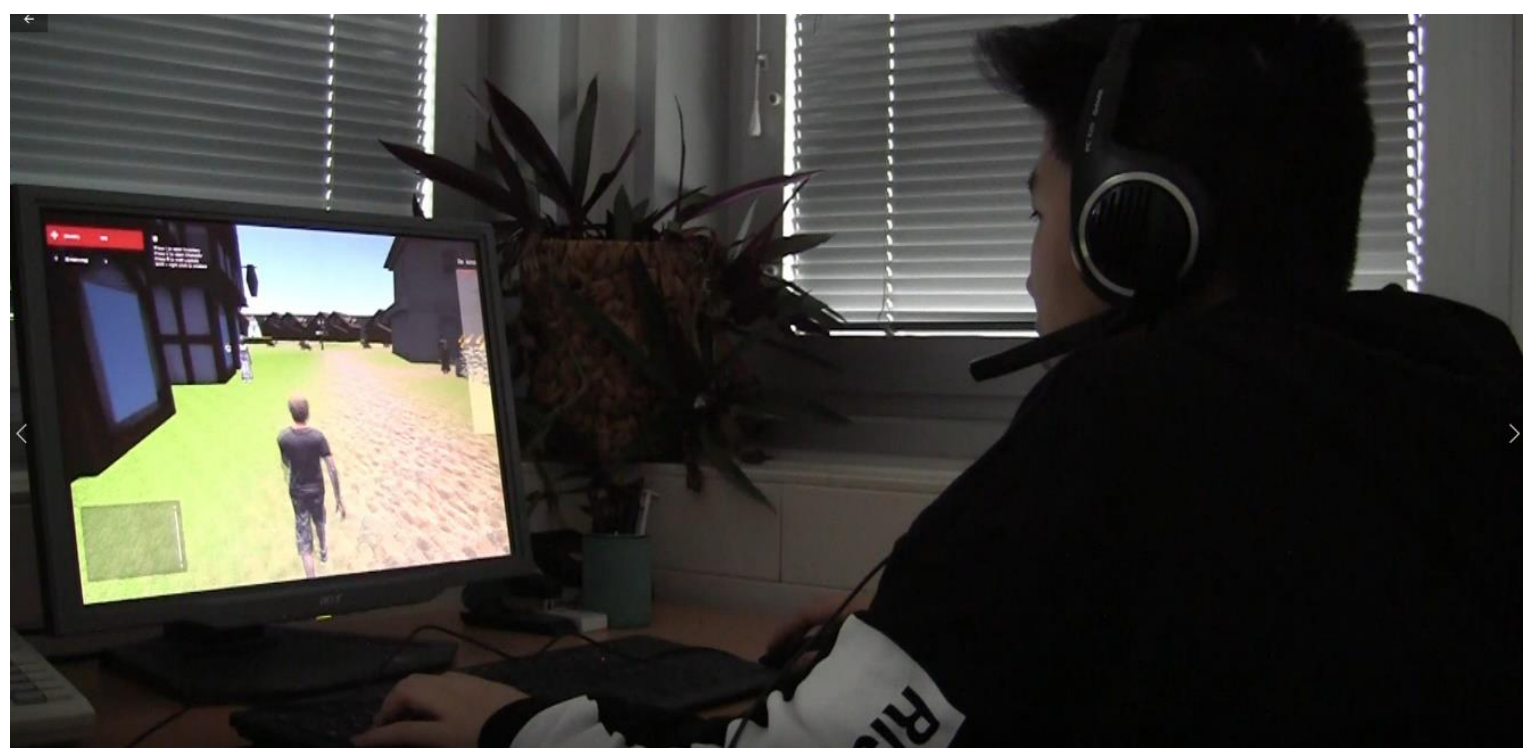

\section{ALCHEMIST gameplay}

In the Alchemist game, the avatar is a high school student who is interested in learning how to convert sand into gold, which he gets to know is possible through an announcement at the university to learn how to change sand into gold, he needs to travel back in time to meet the Alchemist, and he does so by collecting information and solving problems. Some problems contain sub-problems, some of them are fantasy, and others have a real scientific background.

The game starts with an introduction video at the University with an announcement:" See the chemistry teacher if you need to learn how to convert sand into gold". Then, the player goes into the first phase of our problem-solving model and makes contact with the chemistry teacher in an interactive discussion through the dialog system. Through this interactive dialogue, he gets an overview of the gameplay, the main scientific problem and the primary tasks. In the second phase, the player has to collect scientific information. He has to communicate and help the non-player characters (NPC) as a subproblem. To complete this phase; the player has to go outside the city and must free a child from the goblins, which are stealing the city goods. Before he gets out of the city, he has to 
reflect on his understanding of the collected information by answering some questions. Then he goes to the jungle.

In this phase, he will collect items and chemicals after fighting goblins. In the end, the student is expected to have information and chemical elements, and he should conduct some simple experiments to classify the goods into acids and bases by using different indicators in a virtual laboratory. By the end of this phase, he will be able to finish the last level of the game and answer a quiz and open-ended questions that reflect his understanding.

This game contains various tasks and situations which provide an educational goal of learning and assessing chemistry knowledge of acids, bases and indicators. The student has to contact people and collect information, solve sub-problems and answer questions after each phase. After collecting information, the student has to solve some problems by fighting the goblins and collecting a virtual object. After this phase, the student should carry out some experiments through the inventory as a last step in the game to classify these elements into acids and bases by using different indicators. If the student succeeds at this stage, he will be able to finish the game by answering some questions that reflect his understanding. The game offers different actions available which require different levels of understanding and skills and a different score. The evaluation of the student's performance on problem-solving depends on the analysis of the log files for each problem set. The experience score and levels reflect the level of the gained knowledge and good interaction with the game.

\section{Result and Discussion}

The aim of this study is to present how to implement the constructive learning theory and self-determination theory into a video game. This video game is designed as a new kind 
of teaching tool for chemistry concepts and as an assessment tool for domain-specific problem-solving competence, by applying a problem-solving model and the factors of selfdetermination theory through game elements. These types of video games are designed not only to have fun and motivate students, but also to help the teachers and educators to assess their students according to their weaknesses and strengths in each particular phase of the competence. Thus, educators could improve their teaching strategy or use the tools to improve weak areas. Based on this idea, we developed ALCHEMIST. ALCHEMIST targeted the 9th-grade students in the German chemistry curriculum. The scientific content is about acids, bases, and indicators, and is designed and based on the problem-solving model to access this competence of the students. The 3D game framework was chosen for this game since it makes the game efficient, interactive and drives it into more virtual reality. The designing process was complicated, as it includes multidisciplinary work across psychology, design, scientific content, development and programming, which makes it challenging. To cover these points, we followed a game design model, adding some steps to cover the educational needs and the aim of the game.

In order to make the game more effective and interactive, and to drive it into a more virtual world, the 3D game framework was chosen for this game since for this age group a 3D educational game is expected to be more effective (Gunter et al. 2008; Terzidou et al. 2012). Moreover, the use of avatars in the 3D virtual environment establishes non-verbal communication (NVC) features, which can foster collaboration interactions, and enhance the student's ability to apply abstract knowledge later in reality (Dede, 1992; Tsiatsos and Terzidou, 2010). The log file provided shows the player points and gameplay path which indicates the performance levels for each problem set. Also, it can help teachers to evaluate each particular phase of problem-solving competence. After the success of the development of our game-based theoretical background, it will be tested and validated by experts in chemistry education. This validation process should examine if the problem- 
solving model is correctly applied and test the significance of the game design, scientific content and the game's objective.

It may also be of interest to develop such video games with scientific content and educational background in other fields. It also would be a success for the scientist to apply the scientific content through a fantasy 3D video game to the students at different ages to have fun, to learn, and to assess their competencies.

\section{Acknowledgements}

The authors would like to thank their colleagues from the work group of Professor Tiemann, who helped during the game design especially Dr.Andrea Zehl. Dr. Petra Esperling for constructive criticism of the manuscript.

\section{References}

Angawi, R. F. (2014). Using a Problem Solving-Cooperative Learning Approach To Improve Students' Skills for Interpreting 1H NMR Spectra of Un- known Compounds in an Organic Spectroscopy Course. Journal of Chemical Education, 91(6):823-829.

Baylor, A. L. and Kim, Y. (2005). Simulating instructional roles through peda- gogical agents. International Journal of Artificial Intelligence in Education, 15(2):95-115.

Bodner, G. M. and Herron, J. D. (2002). PROBLEM SOLVING IN CHEM- ISTRY.

Chung, G. K., de Vries, L. F., Cheak, A. M., Stevens, R. H., and Bewley, W. L. (2002). Cognitive Validation of a Computer-Based Assessment of Problem Solving: Linking Cognitive and Online Processes. age, 7:1.

Clark, D. B. and Martinez-Garza, M. (2012). 18 Prediction and Explanation as Design Mechanics in Conceptually Integrated Digital Games to Help Players Articulate the Tacit Understandings They Build through Game Play. Games, learning, and society: Learning and meaning in the digital age, page 279.

Cutumisu, M. and Bulut, O. (2017). Problem-Solving Attitudes and Gender as Predictors of Academic Achievement in Mathematics and Science for Canadian and Finnish Students in the PISA 2012 Assessment. In EdMedia+ Innovate Learning, pages 728738.

Dede, C. J. (1992). The future of multimedia: Bridging to virtual worlds. Educational Technology, 32(5), 54-60.

Deterding, S. (2012). Gamification: designing for motivation. interactions, 19(4):14-17.

Eow, Y. L., Baki, R., et al. (2009). Form one students' engagement with computer games and its effect on their academic achievement in a Malaysian secondary school. Computers \& Education, 53(4):1082-1091.

Garris, R., Ahlers, R., and Driskell, J. E. (2002). Games, motivation, and learning: A research and practice model. Simulation \& Gaming, 33(4):441-467.

Greiff, S. and Funke, J. (2009). Measuring complex problem solving: The MicroDYN 
approach. Main, (September):1-6.

Groff, J. (2013). Technology-rich innovative learning environments. OCED CERI Innovative Learning Environment project, 2013:1-30.

Gunter, G. A., Kenny, R. F., \& Vick, E. H. (2008). Taking educational games seriously: using the RETAIN model to design endogenous fantasy into standalone educational games. Educational technology research and Development, 56(5-6), 511-537.

Habgood, M. J. and Ainsworth, S. E. (2011). Motivating children to learn effectively: Exploring the value of intrinsic integration in educational games. The Journal of the Learning Sciences, 20(2):169-206.

Hartig, J., Klieme, E., and Leutner, D. (2008). Assessment of Competencies in Educational Contexts.

Huynh-Kim-Bang, B., Wisdom, J., and Labat, J.-M. (2010). Design patterns in serious games: A blue print for combining fun and learning. Project $S E-S G$.

Jonassen, D. H. (1999). Designing constructivist learning environments. Instructional design theories and models: A new paradigm of instructional theory, 2:215-239.

Jonassen, D. H. (2000). Toward a design theory of problem solving. Educa- tional Technology Research and Development, 48(4):63-85.

Jonassen, D. H. and Kwon, H. (2001). Communication patterns in computer mediated versus face-to-face group problem solving. Educational technology research and development, $49(1): 35$.

Kapp, K. M. (2012). The Gamification of Learning and Instruction: Game- based Methods and Strategies for Training and Education.

$\mathrm{Ke}, \mathrm{F}$. (2011). A qualitative meta-analysis of computer games as learning tools.

Kim, J.-N. and Grunig, J. E. (2011). Problem Solving and Communicative Ac- tion: A Situational Theory of Problem Solving. Journal of Communication, 61(1):120-149.

Klieme, E. (2004). Assessment of cross-curricular problem-solving competen-cies.

Koppelt, J. and Tiemann, R. (2007). Modellierung dynamischer Problem- lösekompetenz im Chemieunterricht - Sowiport.

Malone, T. W. and Lepper, M. R. (1987). Making learning fun: A taxonomy of intrinsic motivations for learning. Aptitude, learning and instruction, 3.

McFarlane, A., Sparrowhawk, A., Heald, Y., et al. (2002). Report on the educa-tional use of games. TEEM (Teachers evaluating educational multimedia), Cambridge.

Mekler, E. D., Brühlmann, F., Tuch, A. N., and Opwis, K. (2017). Towards understanding the effects of individual gamification elements on intrinsic motivation and performance. Computers in Human Behavior, 71:525-534.

Mitchell, A. and Savill-Smith, C. (2004). The use of computer and video games for learning: A review of the literature.

Nasrudin, A. R., Setiawan, W., \& Sanjaya, Y. (2017, May). Impact of audio narrated animation on students' understanding and learning environment based on gender. In AIP Conference Proceedings (Vol. 1848, No. 1, p. 060007). AIP Publishing.

OECD (2013). Assessment and Analytical Framework: Mathematics, Reading, Science, Problem Solving and Financial Literacy. OECD Publishing, Paris. Paraskeva, F., Bouta, H., and Papagianni, A. (2008). Individual characteristics and computer selfefficacy in secondary education teachers to integrate technology in educational practice. Computers \& Education, 50(3):1084-1091.

Peng, W., Lin, J.-H., Pfeiffer, K. A., and Winn, B. (2012). Need satisfaction supportive game features as motivational determinants: An experimental study of a self-determination theory guided exergame. Media Psychology, 15(2):175-196.

Perrotta, C., Featherstone, G., Aston, H., and Houghton, E. (2013). Game- based learning: Latest evidence and future directions.

Prensky, M. (2001). Fun, play and games: What makes games engaging. Digital game-based 
learning, 5:1-05.

Reeff, J. P., Zabal, A., and Blech, C. (2006). The Evaluation of Problem- Solving Competencies.

Ryan, R. M. and Deci, E. L. (2000). Self-determination theory and the facilitation of intrinsic motivation, social development, and well-being. The American Psychologist, 55(1):68-78. C:4XQMTQ.pdf.

Salen, K. and Zimmerman, E. (2004). Rules of play: Game design fundamen-tals.

Scherer, R., koppelt, J., and Tiemann, R. (2014). Developing a computer- based assessment of complex problem solving in Chemistry. null, (Wirth 2008):1-15.

Schrope, M. (2013). Solving tough problems with games. Proceedings of the National Academy of Sciences of the United States of America, 110(18):7104-7106.

Shin, N., Jonassen, D. H., and McGee, S. (2003). Predictors of well-structured and ill-structured problem solving in an astronomy simulation. Journal of Research in Science Teaching, 40(1):6-33.

Shute, V. and Wang, L. (2009). Assessing and Supporting Hard-to-Measure Constructs in Video Games. The Wiley Handbook of Cognition and Assess- ment: Frameworks, Methodologies, and Applications, page 535-562.

Shute, V. J. and Ventura, M. (2013). Measuring and supporting learning in games: Stealth assessment.

Shute, V. J., Ventura, M., and Kim, Y. J. (2013). Assessment and learning of qualitative physics in newtonś playground. The Journal of Educational Research, 106(6):423430 .

Shute, V. J., Wang, L., Greiff, S., Zhao, W., and Moore, G. (2016). Measuring problem solving skills via stealth assessment in an engaging video game. Computers in Human Behavior, 63:106-117.

Terzidou, T., Tsiatsos, T., Dae, A., Samaras, O., \& Chasanidou, A. (2012, July). Utilizing virtual worlds for game based learning: Grafica, a 3D educational game in second life. In 2012 IEEE 12th International Conference on Advanced Learning Technologies (pp. 624-628). IEEE.

Tsiatsos, T., \& Terzidou, T. (2010, July). Supporting collaborative learning processes in CVEs by augmenting student avatars, with nonverbal communication features. In 2010 10th IEEE International Conference on Advanced Learning Technologies (pp. 578-580). IEEE.

Tüzün, H., Y-Soylu, M., Karakuş, T., İnal, Y., and K, G. (2009). The effects of computer games on primary school students' achievement and motivation in geography learning. Computers \& Education, 52(1):68-77.

Wirth, J. and Klieme, E. (2003). Computer-based Assessment of Problem Solving Competence. Assessment in Education: Principles, Policy \& Prac- tice, 10(3):329345.

Yee, N. (2006). Motivations for play in online games. CyberPsychology \& behavior, 9(6):772-775.

Yoon, H., Woo, A. J., Treagust, D., and Chandrasegaran, A. (2014). The Ef- ficacy of Problembased Learning in an Analytical Laboratory Course for Pre-service Chemistry Teachers. International Journal of Science Education, 36(1):79-102.

Zichermann, G. (2010). Fun is the future: Mastering gamification.

Zin, N. A. M., Jaafar, A., and Yue, W. S. (2009). Digital game-based learning (DGBL) model and development methodology for teaching history. WSEAS transactions on computers, 8(2):322-333. 


\section{Biography}

Amany Annaggar scientific co-worker in chemistry education at Humboldt-Universität zu Berlin, Germany, and worked in different projects on inquiry based science learning by the European Union. She obtained a special diploma in educational technology from Helwan University, Egypt, and wrote her master thesis at Humboldt Universität zu Berlin. Amany designed and developed "Alchemist" video game and did her research on it within the scope of her Ph.D. project.

Rüdiger Tiemann is a full professor of chemistry education at Humboldt-Universität zu Berlin, Germany He is a member of the European Association on Research of Learning and Instruction, the National Association on Research on Science Teaching and the Association of Chemistry and Physics Education where he is a board member since 2005. Prof. Tiemann is a reviewer for international and national conferences and journals. He is the head of new implemented division of chemistry education at Humboldt-University and holds a full research university professorship. He has experienced in national and international comparison studies and is responsible for numerous research projects. He brings his results by modern teacher training seminars into schools. 